\title{
Evaluation of the impact of an iodine supplementation programme on severely iodine-deficient schoolchildren with hypothyroidism
}

\author{
Nahid Salarkia ${ }^{1}$, Mehdi Hedayati ${ }^{2}$, Parvin Mirmiran ${ }^{2}$, Masood Kimiagar $^{1}$ and \\ Fereidoun Azizi ${ }^{2, *}$ \\ ${ }^{1}$ National Nutrition Research Institute, Shaheed Beheshti University of Medical Sciences, Tehran, \\ Islamic Republic of Iran: ${ }^{2}$ Endocrine Research Center, Shaheed Beheshti University of Medical Sciences, \\ PO Box 19395-4763, Tehran, Islamic Republic of Iran
}

Submitted 27 November 2001: Accepted 10 February 2003

\begin{abstract}
Background: Northern rural areas of Tehran have been shown to have severe iodine deficiency in our previous studies. In 1989 the inhabitants of these villages received an injection of iodised oil, followed by iodised salt distribution in 1993. The aim of the present study was to evaluate the effect of the iodine supplementation on iodinedeficient schoolchildren with hypothyroidism in these villages.

Methods: In total, 571 students aged 6-14 years were studied. Goitre was graded according to the World Health Organization classification. Serum concentrations of thyroid hormones (thyroxine $\left(\mathrm{T}_{4}\right)$ and triiodothyronine $\left(\mathrm{T}_{3}\right)$ ) and thyroid-stimulating hormone (TSH) were determined using commercial kits, and urinary iodine was measured using a digestion method. The results were compared with data from our previous study in 1989.

Results: Total goitre rate decreased by $42 \%$ in 1999 compared with that in 1989. A significant decrease in Grade 2 goitre concomitant with an increase in Grade 1 goitre was seen $(P<0.001)$. Values of the variables studied before (1989) and 10 years after iodine supplementation (1999) were: median urinary iodine excretion, 2.0 vs. $19.0 \mu \mathrm{g} \mathrm{dl}^{-1} \quad(P<0.001) ; \quad \mathrm{T}_{4}, \quad 6.5 \pm 2.0 \quad$ vs. $8.4 \pm 1.6 \mu \mathrm{g} \mathrm{dl}^{-1} \quad(P<0.001)$; $\mathrm{T}_{3}, \quad 177 \pm 38.0 \quad$ vs. $145 \pm 29.0 \mathrm{ng} \mathrm{dl}^{-1} \quad(P<0.001) ; \mathrm{TSH}, 10.8 \pm 15.1$ vs. $1.8 \pm 0.8 \mu \mathrm{U} \mathrm{ml}^{-1}(P<0.001)$. No correlation was found between thyroid hormones and TSH on the one hand, and goitre and urinary iodine, on the other. Serum $\mathrm{T}_{4}, \mathrm{~T}_{3}$ and TSH concentrations were within normal ranges in all schoolchildren in 1999. Conclusion: This study showed that euthyroidism induced by administration of iodised oil in iodine-deficient schoolchildren with hypothyroidism is sustained following the consumption of iodised salt.
\end{abstract}

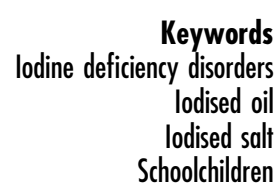

Iodine deficiency is one of the most important causes of mental impairment and has serious consequences on physical development ${ }^{1}$. The most notable clinical sign of iodine deficiency is goitre. Universal salt iodisation is the mainstay of prevention of iodine deficiency. However, administration of iodised oil is recommended for prevention in severe endemic areas where iodised salt is not available, as well as for treatment in areas with hypothyroidism due to severe iodine deficiency ${ }^{2}$. It has been shown that iodised oil treatment may improve mental and psychometric performance in school-aged children.

Iodine deficiency disorders (IDD) are one of the main public health issues in $\operatorname{Iran}^{3}$. Northern rural areas of Tehran have been known as areas of severe iodine deficiency ${ }^{4,5}$. These villages are situated in a mountainous region, at an altitude of approximately $2000 \mathrm{~m}$ above sea level, about $35 \mathrm{~km}$ to the north of Tehran. In 1989, the whole population of these villages received an injection of iodised oil. Increases in serum concentrations of the thyroid hormones thyroxine $\left(\mathrm{T}_{4}\right)$ and triiodothyronine $\left(\mathrm{T}_{3}\right)$, and in urinary iodine, and decreases in serum concentrations of thyroid-stimulating hormone (TSH), were observed and reported ${ }^{6,7}$. Iodised salt distribution as the main strategy of the national plan for IDD control was initiated in $1989^{8}$. In northern rural areas of Tehran, however, iodised salt consumption started in 1993 and is ongoing.

The present study was carried out in 1999 to evaluate the impact of the iodine supplementation programme on indicators of iodine deficiency in the above-mentioned villages, 10 years after iodine supplementation. 


\section{Materials and methods}

\section{Baseline data}

In 1989 the total population of northern rural areas of Tehran, namely Kiga, Keshar, Randan, Sangan and Zagoon, who were known to be iodine-deficient ${ }^{4,5}$, were injected with $480 \mathrm{mg}$ iodised oil (Lipiodol ${ }^{\circledR}$ ). Before receiving the iodised oil injection, all pupils aged 6-14 years in Kiga $(n=192)$, Keshar $(n=149)$, Randan $(n=54)$, Sangan $(n=30)$ and Zagoon $(n=20)$ villages were studied in order to determine goitre prevalence, concentrations of thyroid hormones and TSH, as well as urinary iodine excretion.

\section{The 1999 study}

In this study, performed 10 years after administration of the iodised oil injection and 6 years after the initiation of iodised salt consumption, all schoolchildren aged 6-14 years in the five villages were examined clinically and for biochemical status indicators.

\section{Clinical examination}

Goitre size was examined by palpation by an endocrinologist and classified as Grades 0, 1 and 29. A venous blood sample was obtained from each child; serum was separated and stored at $-20^{\circ} \mathrm{C}$ until analysis. Urine samples were collected randomly from the subjects. Casual samples taken from each child were stored in a clean container at $-20^{\circ} \mathrm{C}$ until analysis. All urine samples were transported promptly and analysed in the urinary iodine laboratory at the Endocrine Research Center in Tehran.

\section{Laboratory measurements}

The acid digestion method was employed for analysis of urinary iodine ${ }^{10}$. Serum concentrations of $\mathrm{T}_{4}, \mathrm{~T}_{3}$ and $\mathrm{TSH}$, and $\mathrm{T}_{3}$ resin uptake, were determined with commercial kits from Fenzia, Finland. Free $\mathrm{T}_{4}$ index $\left(\mathrm{FT}_{4} \mathrm{I}\right)$ was calculated $^{11}$. Reference ranges for euthyroid subjects were: $\mathrm{T}_{4}, 4.5-12.5 \mathrm{~g} \mathrm{dl}^{-1} ; \mathrm{T}_{3}, 80-210 \mathrm{ng} \mathrm{dl}^{-1}$; TSH, $<0.3-4.5 \mu \mathrm{Uml}^{-1}$.

\section{Data analysis}

All variables such as goitre size, urinary iodine excretion, serum TSH and thyroid hormone concentrations were determined in each age group in all villages. These data were compared with similar data in 1989 (before intervention) in all villages. Student's $t$-test was employed for quantitative variables and the Chi-square test for goitre size results. $P$-values below 0.05 were considered significant. Correlation among variables was assessed by the Spearman test. This study was approved by the University Human Research Review Committee.

\section{Results}

Total goitre rate decreased by $42 \%$ in 1999, as compared with that in 1989 (Table 1). A significant decrease in Grade 2 goitre was observed: from 94 to $14 \%$ in Kiga, from 66 to 9.4\% in Keshar and from 82 to 9.7\% in Randan $(P<0.001)$ (Fig. 1). Sixty per cent of schoolchildren aged below 10 years and 30\% of students above 10 years did not have goitre. Grade 2 goitre rates in schoolchildren above and below 10 years of age were 3 and 19\%, respectively. For Grade 1 goitre the corresponding values were 37 and 50\%.

Table 2 indicates the median urinary iodine in four villages in 1989 and 1999. In 1989 all villages had median urinary iodine concentration below $2 \mu \mathrm{g} \mathrm{dl}^{-1}$, while in 1999 , the median concentration of urinary iodine in all

Table 1 Total goitre rate in schoolchildren of five villages in northern rural areas of Tehran, before (1989) and 10 years after iodine supplementation (1999)

\begin{tabular}{lrccc}
\hline & & \multicolumn{4}{c}{1999} \\
\cline { 3 - 5 } Village & 1989 & All students & $11-16$ years old & $6-10$ years old \\
\hline Kiga & 100 & 64 & 71 & 58 \\
Keshar & 99 & 52 & 53 & 51 \\
Sangan & 99 & 52 & 56 & 50 \\
Randan & 100 & 61 & 79 & 42 \\
Zagoon & 100 & 54 & 67 & 41 \\
Total & 99 & 57 & 72 & 41 \\
\hline
\end{tabular}

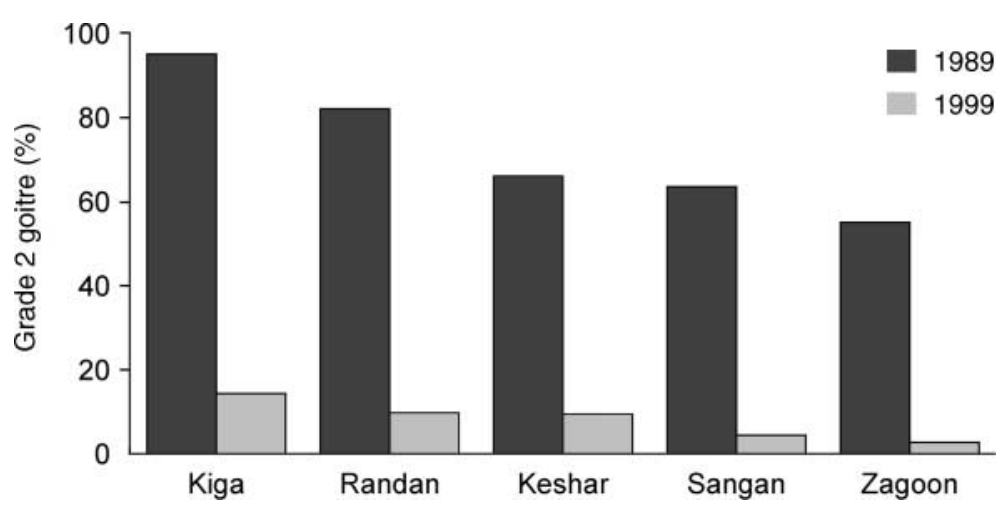

Fig. 1 Prevalence of Grade 2 goitre in schoolchildren of five villages in northern rural areas of Tehran, before (1989) and 10 years after iodine supplementation (1999). The changes in goitre prevalence and severity were statistically significant in all villages at $P<0.001$ 
Table 2 Median urinary iodine concentration in schoolchildren of four villages in northern rural areas of Tehran, before (1989) and 10 years after iodine supplementation (1999)

\begin{tabular}{lll}
\hline & \multicolumn{2}{c}{ Urinary iodine excretion $\left(\mu \mathrm{g} \mathrm{dl}^{-1}\right)$} \\
\cline { 2 - 3 } Village & \multicolumn{1}{c}{1989} & 1999 \\
\hline Kiga & $1.9(49) \dagger$ & $20.1^{*}(61)$ \\
Keshar & $1.8(15)$ & $20.1^{*}(135)$ \\
Randan & $1.2(25)$ & $17.3^{*}(28)$ \\
Zagoon & $1.8(22)$ & $20.1^{*}(89)$ \\
\hline
\end{tabular}

${ }^{*} P<0.001$, as compared with 1989

$\dagger$ The number of subjects is given in parentheses.

villages was above $17 \mu \mathrm{g} \mathrm{dl}^{-1}$ ( $\left.P<0.001\right)$. In 1999, 96\% of subjects had values above $10 \mu \mathrm{g} \mathrm{dl}^{-1}$ with none below $5 \mu \mathrm{g} \mathrm{dl}{ }^{-1}$.

Table 3 compares mean hormone levels in 1989 and 1999 in each village. In 1989 many of the schoolchildren had hypothyroidism. Forty per cent of the schoolchildren in Kiga and 24\% of those in Kesher had serum TSH levels above $10 \mu \mathrm{U} \mathrm{ml}^{-1}$. TSH values between 5 and $10 \mu \mathrm{Uml}^{-1}$ were observed in $30 \%$ of children in Kiga and $22 \%$ of children in Randan.

Serum $\mathrm{T}_{4}, \mathrm{~T}_{3}$ and $\mathrm{TSH}$ concentrations, $\mathrm{FT}_{4} \mathrm{I}$ and resin $\mathrm{T}_{3}$ uptake level were normal in all schoolchildren in 1999. No correlation was established between thyroid hormones, urinary iodine and grades of goitre.

\section{Discussion}

This study demonstrates that iodine prophylaxis restored euthyroidism in those subjects who had hypothyroidism, and prevented the consequences of iodine deficiency in the rest.
In subjects with goitre and iodine deficiency, iodine supplementation results in elevated thyroid iodine concentration $^{12}$ as well as a decrease in goitre prevalence and severity ${ }^{13-15}$. The effects of iodine supplementation on the thyroid status of subjects with hypothyroidism and endemic goitre have also been reported. Percutaneous application of iodine to iodine-deficient newborns resulted in rapid disappearance of goitre and normalised serum $\mathrm{T}_{4}$ and $\mathrm{TSH}$ levels within 5 days ${ }^{16}$. Iodised oil injection in children with endemic cretinism in Zaire resulted in decreased $\mathrm{TSH}$ and increased $\mathrm{T}_{4}$ concentrations ${ }^{17}$. Greater changes were observed in children below 4 years of age, however, who attained normal TSH and $\mathrm{T}_{4}$ levels 5 months following injection. In 14 children aged 4 to 14 years, only a partial response was seen. Administration of iodised oil did not reverse thyroid hormone deficiency in adolescents and adults with endemic myxoedematous cretinism in western China ${ }^{18}$. We have reported, both in boys $^{6}$ and girls ${ }^{7}$ residing in Kiga, that the injection of iodised oil restores euthyroidism within 4 months of injection, perhaps due to the lesser severity of the lesion, since all children in Kiga had goitrous hypothyroidism and none had atrophic gland.

Iodised salt supplementation is the method of choice for prevention of IDD 9 . Therefore, in the present study, 4 years following iodised oil administration, while its effect was diminishing, distribution and consumption of iodised salt was applied, which had a complementary effect in the control of iodine deficiency. The decrease in goitre prevalence was appreciable 10 years after iodine prophylaxis and both the prevalence and severity of goitre decreased. Similar results have been obtained in other countries $^{19-23}$. However, more than a third of children

Table 3 Serum concentrations of thyroxine $\left(T_{4}\right)$, triiodothyronine $\left(T_{3}\right)$ and thyroid-stimulating hormone (TSH), $T_{3}$ resin uptake $\left(\mathrm{RT}_{3} \mathrm{Up}\right)$ and free $\mathrm{T}_{4}$ index $\left(\mathrm{FT}_{4} \mathrm{I}\right)$ in schoolchildren of five villages in northern rural areas of Tehran, before (1989) and 10 years after iodine supplementation (1999)

\begin{tabular}{|c|c|c|c|c|c|}
\hline \multirow[b]{2}{*}{ Village } & \multicolumn{5}{|c|}{ Serum concentration } \\
\hline & $\mathrm{T}_{4}\left(\mu \mathrm{gdl}^{-1}\right)$ & $\mathrm{T}_{3}\left(\mathrm{ng} \mathrm{dl}^{-1}\right)$ & $\mathrm{TSH}\left(\mu \cup \mathrm{ml}^{-1}\right)$ & $\mathrm{RT}_{3} \mathrm{Up}(\%)$ & $\mathrm{FT}_{4} \mathrm{I}$ \\
\hline \multicolumn{6}{|l|}{ Kiga } \\
\hline $1989(n=95)$ & $5.1 \pm 2.0$ & $162 \pm 38$ & $19.7 \pm 29.7$ & $28.0 \pm 1.7$ & $1.4 \pm 0.6$ \\
\hline $1999(n=66)$ & $8.8 \pm 1.8^{*}$ & $149 \pm 27 \dagger$ & $1.9 \pm 0.7^{\star}$ & $27.0 \pm 1.9$ & $2.4 \pm 0.6$ \\
\hline \multicolumn{6}{|l|}{ Keshar } \\
\hline $1989(n=103)$ & $8.4 \pm 2.1$ & $179 \pm 39$ & $3.3 \pm 4.2$ & $27.0 \pm 2.1$ & $2.3 \pm 0.6$ \\
\hline $1999(n=138)$ & $8.9 \pm 1.7$ & $152 \pm 31 \dagger$ & $1.7 \pm 8.8^{*}$ & $27.0 \pm 2.7$ & $2.4 \pm 0.5$ \\
\hline \multicolumn{6}{|l|}{ Sangan } \\
\hline $1989(n=84)$ & $8.1 \pm 2.2$ & $136 \pm 24$ & $3.4 \pm 6.7$ & $28.0 \pm 3.0$ & $2.3 \pm 0.6$ \\
\hline $1999(n=87)$ & $7.6 \pm 1.4$ & $140 \pm 30$ & $1.9 \pm 1.3^{*}$ & $26.5 \pm 1.7$ & $2.0 \pm 0.4$ \\
\hline \multicolumn{6}{|l|}{ Randan } \\
\hline $1989(n=54)$ & $6.0 \pm 1.8$ & $189 \pm 37$ & $9.4 \pm 11.6$ & $25.0 \pm 2.0$ & $1.5 \pm 0.5$ \\
\hline $1999(n=28)$ & $7.6 \pm 1.4^{*}$ & $134 \pm 20^{*}$ & $1.7 \pm 0.8^{*}$ & $27.0 \pm 1.3$ & $2.0 \pm 0.5$ \\
\hline \multicolumn{6}{|l|}{ Zagoon } \\
\hline $1989(n=20)$ & $7.5 \pm 1.6$ & $168 \pm 30$ & $3.5 \pm 0.9$ & $27.0 \pm 2.0$ & $2.0 \pm 0.5$ \\
\hline $1999(n=99)$ & $9.0 \pm 2.0 \dagger$ & $158 \pm 23$ & $1.5 \pm 0.8^{\star}$ & $27.0 \pm 1.8$ & $2.8 \pm 0.6$ \\
\hline \multicolumn{6}{|l|}{ Total } \\
\hline $1989(n=356)$ & $6.5 \pm 2.0$ & $177 \pm 38$ & $10.8 \pm 15.1$ & $26.0 \pm 2.3$ & $1.9 \pm 0.6$ \\
\hline $1999(n=418)$ & $8.4 \pm 1.6^{*}$ & $145 \pm 29^{*}$ & $1.8 \pm 0.8^{*}$ & $27.0 \pm 1.8$ & $2.2 \pm 0.5$ \\
\hline
\end{tabular}

${ }^{*} P<0.001 ; \dagger P<0.05$; as compared with 1989. 
aged 6-10 years still had goitre. It has been shown that thyroid size in children exposed to iodine deficiency in the first years of life might fail to regress completely following the consumption of iodised salt ${ }^{24}$. However, palpation of the thyroid in not a precise method for the estimation of thyroid size; therefore, some of the findings might be due to the inaccuracy of the palpation method.

Median urinary iodine of $17.3-20.1 \mu \mathrm{g} \mathrm{dl}^{-1}$ in the villages studied shows adequate iodine intake ${ }^{9}$ and the propriety of the $40 \mathrm{ppm}$ iodised salt programme in Iran, as shown in our previous report ${ }^{8}$. Iodine supplementation has been recognised to increase the incidence of hyperthyroidism in iodine-deficient areas ${ }^{25,26}$. Increases in $\mathrm{T}_{4}$ and $\mathrm{T}_{3}$ and decreases in $\mathrm{TSH}$ were observed in Kiga in the first year after iodised oil administration ${ }^{7}$. Thyroid function returned to normal, however, within a year and has remained so after 10 years. No untoward effects have occurred with respect to possible hyperthyroidism. It has to be taken into consideration, however, that the population studied was young schoolchildren and 10 years has passed since the initiation of iodine supplementation. Iodine-induced thyrotoxicosis is seen mainly in adults, and in particular the elderly, usually one to two years following intervention ${ }^{26}$.

In conclusion, this study demonstrates that in children and adolescents with depressed thyroid function due to iodine deficiency, who had restoration of euthyroidism after iodised oil supplementation, normal thyroid function is sustained following consumption of iodised salt. Many children and adolescents residing in iodine-deficient regions may have decreased thyroid function resulting from moderate to severe iodine deficiency that is not grave enough to cause progressive degeneration and atrophy of thyroid tissue. Iodised oil administration appears to be the treatment of choice for these individuals, followed by supplementary iodised salt intake.

\section{References}

1 Hetzel BS. Iodine deficiency disorders (IDD) and their eradication. Lancet 1983; 2: 1126-9.

2 Thilly $\mathrm{CH}$, Delange F, Goldstein-Golaire J, Ermans AM. Endemic goiter prevention by iodized oil: a reassessment. Journal of Clinical Endocrinology and Metabolism 1973; 36(6): 1196-204.

3 Azizi F, Kimiagar M, Nafarabadi M, Yassdi M. Current status of iodine deficiency disorders in the Islamic Republic of Iran. EMR Health Services Journal 1990; 8: 23-7.

4 Azizi F, Sarshar A, Nafarabadi M, Ghazi A, Kimiagar M, Noohi S, et al. Impairment of neuromotor and cognitive development in iodine-deficient schoolchildren with normal physical growth. Acta Endocrinologica 1993; 129: $501-4$.

5 Azizi F, Kalani H, Kimiagar M, Ghazi A, Sarshar A, Nafarabadi $\mathrm{M}$, et al. Physical, neuromotor and intellectual impairment in non-cretinous schoolchildren with iodine deficiency. International Journal for Vitamin and Nutrition Research 1995; 65: 199-205.

6 Azizi F, Kimiagar M, Ghazi A, Nafarabadi M, Behjati J, Esfahanian F. Treatment of goitrous hypothyroidism with iodized oil supplementation in an area of iodine deficiency. Experimental and Clinical Endocrinology \& Diabetes 1996; 104: 387-91.

7 Azizi F, Kimiagar M, Ghazi AA, Nafarabadi M. The effects of iodized oil injection in eu- and hypothyroid iodine deficient girls. Journal of Endocrinological Investigation 1997; 20 $18-23$.

8 Azizi F, Sheikholeslam R, Hedayati M, Mirmiran P, Malekafzali H, Kimiagar M, et al. Sustainable control of iodine deficiency in Iran: beneficial results of the implementation of mandatory law on salt iodization. Journal of Endocrinological Investigation 2002; 25: 409-13.

9 World Health Organization (WHO)/United Nations Children's Fund (UNICEF)/International Council for Control of Iodine Deficiency Disorders (ICCIDD). Assessment of the Iodine Deficiency Disorders and Monitoring their Elimination. Report of Consultation, 4-6 May 1999; A Guide for Programme Managers. WHO/NHD 01.1. Geneva: WHO, 2001.

10 Dunn JT, Crutchfield ME, Gutekunst R, Dunn AD. Methods for Measuring Iodine in Urine. International Council for Control of Iodine Deficiency Disorders (ICCIDD)/United Nations Children's Fund (UNICEF)/World Health Organization (WHO) Publication. Geneva: WHO, 1993.

11 Sawin C, Chopra D, Albano J, Azizi F. The free triiodothyronine (T3) index. Annals of Internal Medicine 1978; 88: 474-7.

12 Leisner B, Henrich B, Knorr D, Kantlehner R. Effect of iodine treatment on iodine concentration and volume of endemic non-toxic goitre in childhood. Acta Endocrinologica 1985; 108: $44-50$.

13 Buttlfield IH, Hetzel BS. Endemic goiter in New Guinea and the prophylactic program with iodinated poppy seed oil. In: Stanbury JB, ed. Endemic Goiter. Washington, DC: Pan American Health Organization, 1969; 132-45.

14 Feirro-Benitez R, Cazar R, Stanbury JB, Rodriguez P, Garces F, Fierro-Renoy $\mathrm{F}$, et al. Long term effect of correction of iodine deficiency on psychomotor and intellectual development. In: Dunn JT, Pretell EA, Daza CH, Witeri FE, eds. Towards the Eradication of Endemic Goiter, Cretinism, and Iodine Deficiency. Washington, DC: Pan American Health Organization, 1986; 182-200.

15 Philips DIW, Osmond C. Iodine supplementation with oral or intramuscular iodized oil. A two-year follow up of a comparative trial. International Journal of Epidemiology 1989; 18: 907-10.

16 Heidemann P, Stubbe P. Serum 3,5,3'-triiodothyronine, thyroxine, and thyrotropin in hypothyroid infants with congenital goiter and the response to iodine. Journal of Clinical Endocrinology and Metabolism 1978; 47: 189-92.

17 Vanderpas JB, Rivera-Vanderpas MT, Bourdoux P, Luvivila K, Lagasse R, Perlmutter-Crener N, et al. Reversibility of severe hypothyroidism with supplementary iodine in patients with endemic cretinism. New England Journal of Medicine 1986; 315: 791-5

18 Boyages SC, Halpern J, Maberly GF, Collins J, Jupp J, Eastman CJ, et al. Supplementary iodine fails to reverse hypothyroidism in adolescents and adults with endemic cretinism. Journal of Clinical Endocrinology and Metabolism 1990; 70: 336-41.

19 Eber O, Wawschinek O, Langsteger W, Lind P, Klima G, Petek W, et al. Iodine supplementation in the province of Styria [in German]. Wiener Medizinische Wochenschrift 1990; 140(9): 241-4.

20 An OY, Su TS, Pang XP, Hershman JM. Measurement of serum TSH level by ultrasensitive methods in inhabitants of endemic goiter area supplied with iodized salt for 25 years. Chinese Medical Journal 1991; 104(12): 971-4.

21 Salvaneschi JP, Salvaneschi BG, Moralejo AB, Garcia JR Endemic goiter in Argentina. Epidemiologic studies before 
(1968) and during (1986) prophylaxis with iodized salt in the city of Buenos Aires. Medicina (Buenos Aires) 1991; 51(2): 99-105.

22 Aghini-Lombardi F, Pinchera A, Antonangeli L, Rago T, Fenzi GF, Nanni P, et al. Iodized salt prophylaxis of endemic goiter: an experience in Toscana (Italy). Acta Endocrinologica 1993; 129(6): 497-500.

23 Thomson CD, Colls AJ, Conaglen MM, Stiles M, Mann AJ. Iodine status of New Zealand residents as assessed by urinary iodide excretion and thyroid hormones. British Journal of Nutrition 1997; 78: 901-12.
24 Aghini-Lombardi F, Antonangeli L, Pinchera A, Leoli F, Rago $\mathrm{T}$, Bartolomei AM, et al. Effect of iodized salt on thyroid volume of children living in an area previously characterized by moderate iodine deficiency. Journal of Clinical Endocrinology and Metabolism 1997; 82: 1136-9.

25 Connolly RJ, Vidor CI, Stewart JC. Increase in thyrotoxicosis in endemic goitre area after iodation of bread. Lancet 1970; 1: $500-2$.

26 Delange F, de Benoist B, Alnwick D. Risks of iodine-induced hyperthyroidism after correction of iodine deficiency by iodized salt. Thyroid 1999; 9: 545-53. 